\title{
Opioid Antagonist Diprenorphine Microinjected into Parabrachial Nucleus Selectively Inhibits Vasopressin Response to Hypovolemic Stimuli in the Rat
}

\author{
Yasumasa Iwasaki, * Mary Beth Gaskill, ${ }^{\star}$ Ronggen Fu, ${ }^{\star}$ Clifford B. Saper, * and Gary L. Robertson, ${ }^{\star}$ \\ * Department of Medicine, and Department of Pharmacological and Physiological Science, The University of Chicago, Chicago, Illinois \\ 60637; and ${ }^{\ddagger}$ Department of Medicine and Neurology, Northwestern University Medical School, Chicago, Ilinois 60611
}

\begin{abstract}
Subcutaneous injection of the potent, nonselective opioid antagonist diprenorphine inhibits the vasopressin response to acute hypovolemia. To determine if this inhibition is due to antagonism of opioid receptors in brain pathways that mediate volume control, we determined the vasopressin response to different stimuli when diprenorphine or other opiates were injected into the cerebral ventricles, the nucleus tractus solitarius (NTS), or the lateral parabrachial nucleus (PBN) of rats. We found that the vasopressin response to hypovolemia was inhibited by injection of diprenorphine into the cerebral ventricles at a dose too low to be effective when given subcutaneously. This response also was inhibited when a 20 -fold lower dose of diprenorphine was injected into the PBN but not when it was injected into the NTS. The inhibitory effect of diprenorphine in the PBN was not attributable to a decrease in osmotic or hypovolemic stimulation and did not occur with osmotic or hypotensive stimuli. Injecting the PBN with equimolar doses of the $\mu$ antagonist naloxone, the $\delta$ antagonist ICI-154,129 or the $\kappa-1$ agonist $\mathrm{U}-\mathbf{5 0 , 4 8 8 \mathrm { H }}$ had no effect on basal or volume-stimulated vasopressin. We conclude that the inhibition of vasopressin by diprenorphine is due partially to action at a novel class of opioid receptors that transmit volume stimuli through the PBN. ( $J$. Clin. Invest. 1993.92:2230-2239.) Key words: blood pressure • blood volume $\bullet$ brain $\bullet$ opioid peptides $\bullet$ osmoregulation
\end{abstract}

\section{Introduction}

Although secretion of the antidiuretic hormone, arginine vasopressin, is regulated primarily by blood osmolality, it can also be stimulated by moderately large reductions in blood volume

This study was presented in part at the Central Society for Clinical Research, Chicago, IL, 2 November 1990 and published in abstract form (1990. Clin. Res. 38:860A).

Dr. Iwasaki's present address is First Department of Internal Medicine, Nagoya University School of Medicine, Nagoya, Japan; Dr. Saper's present address is Department of Neurology, Beth Israel Hospital and Harvard Medical School, Boston, Massachusetts 02114.

Address reprint requests to Dr. Gary L. Robertson, Department of Medicine, Searle 11-580, Northwestern University Medical School, 303 East Chicago Avenue, Chicago, IL 60611-3008.

Received for publication 3 February 1993 and in revised form 24 May 1993.

J. Clin. Invest.

(c) The American Society for Clinical Investigation, Inc. $0021-9738 / 93 / 11 / 2230 / 10 \quad \$ 2.00$

Volume 92, November 1993, 2230-2239 or pressure (1). These hemodynamic influences appear to be relatively unimportant under physiologic conditions but they may be responsible for the disturbances of vasopressin secretion and water balance in many clinical disorders such as heart failure or cirrhosis of the liver (2). Some of the neural pathways that mediate these hemodynamic influences have been elucidated (3-5) but relatively little is known about their neurochemistry.

Recently, we found that subcutaneous injection of diprenorphine, a potent nonselective opioid antagonist (6), almost completely eliminates the plasma vasopressin response to an acute hypovolemic stimulus in conscious rats (7). The drug did not affect basal, unstimulated levels of plasma vasopressin and had little or no inhibitory effect on the hormonal response to osmotic or hypotensive stimuli. This selectivity suggested that diprenorphine inhibits the vasopressin response to acute hypovolemia by antagonizing opioidergic neurotransmission at one or more sites along the afferent pathways that transmit signals from peripheral volume receptors to the neurohypophysis. To test this hypothesis, we have performed a series of experiments to determine if the vasopressin response to hypovolemic, osmotic, or hypotensive stimuli is inhibited by injecting small doses of diprenorphine into the cerebral ventricles, the nucleus tractus solitarius (NTS), ${ }^{1}$ or the lateral parabrachial nucleus (PBN). These two nuclei were selected as likely candidates for the site of the inhibitory action of diprenorphine because they both contain large numbers of opioidergic peptides and/or receptors $(8,9)$ and appear to play an important role in the hemodynamic control of vasopressin secretion (1016). To clarify the mechanism of action of diprenorphine, we also determined the effects of injecting the PBN with naloxone, a prototype $\mu$ antagonist, ICI-154,129, a selective $\delta$ antagonist (17), or $\mathrm{U}-50,488 \mathrm{H}$, a potent $\kappa$ agonist $(18,19)$.

\section{Methods}

\section{Animals}

Male Sprague-Dawley rats ( $300-400$ g, Sasco, Omaha, NE) were maintained on standard rat laboratory diet and tap water in a temperature-, humidity-, and light-controlled vivarium for $7 \mathrm{~d}$ (lights on from $6 \mathrm{a} . \mathrm{m}$. to 6 p.m.). Only those that gained weight normally or showed no evidence of illness were studied. Rats were allowed to eat and drink ad libitum until the start of experiment.

\section{Drugs}

Diprenorphine was supplied by the National Institute on Drug Abuse (Bethesda, MD). It was stored at room temperature until the day of the

1. Abbreviations used in this paper: NTS, nucleus tractus solitarius; PBN, parabrachial nucleus; PEG, polyethylene glycol. 
experiment, when it was dissolved in physiologic saline at concentrations of 0.22 or $2.2 \mu \mathrm{M}$ for subcutaneous (s.c.) injection; at 8.8 or 88 $\mu \mathrm{M}$ for injection into the cerebral ventricle (i.c.v.); at 45, 83, or $165 \mu \mathrm{M}$ for microinjection into specific nuclei. Naloxone (Endo Laboratories, Wilmington, DE) was stored at room temperature until the day of the microinjection experiment when it was dissolved in physiologic saline at a concentration of $83 \mu \mathrm{M}$. ICI-154,129 (a gift from Dr. M. Rance, Imperial Chemical Industries PLC, Cheshire, UK) was stored at $4^{\circ} \mathrm{C}$ until the day of the microinjection experiment when it was dissolved in physiologic saline at a concentration of $83 \mu \mathrm{M}$. U-50,488H ( a gift from Dr. P. VonVoigtlander, The Upjohn Co., Kalamazoo, MI) was stored at $4^{\circ} \mathrm{C}$ until the day of the experiment when it was dissolved in physiologic saline at a concentration of $100 \mu \mathrm{M}$.

\section{Basic experimental protocol}

Vasopressin stimulation. Three kinds of stimuli were used: (a) Acute isotonic hypovolemia was induced $(20)$ by giving an intraperitoneal (i.p.) injection of $20 \mathrm{ml} / \mathrm{kg}$ body weight of normal saline containing 20\% (wt/ vol) polyethylene glycol (PEG) 3350 (Sigma Chemical Co., St. Louis, MO). (b) Acute, normovolemic hyperosmolality was induced (20) by giving an i.p. injection of $20 \mathrm{ml} / \mathrm{kg}$ body weight of hypertonic $(600 \mathrm{mmol} / \mathrm{kg})$ saline. (c) Acute hypotension was induced (7) by giving a s.c. injection of $1 \mathrm{ml} / \mathrm{kg}$ body weight of $0.1 \%(\mathrm{wt} / \mathrm{vol})$ sodium nitroprusside (Sigma Chemical Co.) in normal saline.

Opioid administration. Opioids were injected three ways. Injections s.c. $(1 \mathrm{ml} / \mathrm{kg})$ were given at the back of the neck with a 20 -gauge needle. Injections i.c.v. were given via chronically implanted cannulae. For this purpose, rats were anesthetized with pentobarbital, $60 \mathrm{mg} / \mathrm{kg}$ i.p., and ketamine $\mathrm{HCl}, 21 \mathrm{mg} / \mathrm{kg}$ intramuscular (i.m.), then fixed in a stereotaxic apparatus (David Kopf Instruments, Tujunga, CA) with the incisor bar $5 \mathrm{~mm}$ above the intraaural line. After incising the scalp in the midline, a fine hole was drilled $0.3 \mathrm{~mm}$ posterior and $1.5 \mathrm{~mm}$ to the right of the bregma and a sterile 27-gauge stainless needle was inserted $4.5 \mathrm{~mm}$ below the surface of the skull into the right lateral ventricle. After the cannula was secured to the skull with acrylic cement, the scalp was closed with skin clips and the animals were placed in individual cages for $7 \mathrm{~d}$ and supplied with drinking water containing an oral antibiotic, erythromycin. Only those rats which regained their preoperative weight and showed no evidence of infection were studied. On the day of the experiment, a polyethylene tube (PE-20) containing normal saline with or without the drug was connected to a $10-\mu$ l Hamilton syringe and $25 \mu \mathrm{l} / \mathrm{kg}$ of solution was injected over a period of $2 \mathrm{~min} .30$ min later, the rats were killed by decapitation and their trunk blood was collected for subsequent analysis. To verify positioning, the i.c.v. cannulae were injected with the same volume of India ink immediately after decapitation of the animal, and the brain was removed, hand-sectioned, and inspected. If the ink was not clearly visible outlining at least one lateral ventricle, the data from that rat were excluded from analysis.

Microinjections into specific brain nuclei were given acutely under general anesthesia. For this purpose, $\alpha$-chloralose, $75 \mathrm{mg} / \mathrm{kg}$ i.p., was used because this drug has been shown to interfere minimally, if at all, with cardiovascular reflexes (21) and, in our preliminary experiments, it did not affect either basal or volume-stimulated levels of plasma vasopressin (not shown). For injections of the NTS, rats were placed in a stereotaxic frame with the incisor bar $13 \mathrm{~mm}$ below the interaural line, and the dorsal surface of the medulla was exposed by removal of the muscle insertions on the occipital bone and the atlanto-occipital membrane. The obex was identified through a stereoscopic microscope and the pipet was lowered to the calamus scriptorius, which served as the rostral-caudal (AP) and medio-lateral (ML) zero reference. The prewarmed $\left(37^{\circ} \mathrm{C}\right)$ solution of saline and methylene blue with or without added drug was then drawn into a fine glass micropipette (tip o.d. 50-60 $\mu \mathrm{m}$ ) which was placed in a micromanipulator, positioned over the intermediate portion of NTS (AP, $+0.25 \mathrm{~mm}$; ML, $+0.5 \mathrm{~mm}$ ), and lowered $0.5 \mathrm{~mm}$ beneath the dorsal surface of the brainstem. Exactly $200 \mathrm{nl}$ of the solution was injected bilaterally in $2 \mathrm{~min}$ and the micropipette was left in the brainstem for another minute to prevent regurgita- tion of the injectate through the needle track. The injection was then repeated on the other side. Both times, after the needle was withdrawn, its patency was confirmed by visual confirmation of flow through its tip. If no flow was observed, the rat was removed from the study. For microinjection into the PBN, rats were prepared the same way and placed in a stereotaxic frame with the incisor bar at the interaural line. The scalp was incised, small holes were drilled bilaterally in the skull, and the tip of the micropipette was lowered to a point corresponding to the dorsolateral part of PBN (AP, $-0.6 \mathrm{~mm}$; ML, $+1.9 \mathrm{~mm}, \mathrm{DV}+3.6$ $\mathrm{mm}$ from the midpoint of interaural line). The saline/methylene blue solution with or without added drug was microinjected in the same manner as into the NTS.

30 min after injection of the drug, the rats were killed by decapitation and the trunk blood was collected in chilled heparinized tubes. The brain was removed intact, immersed overnight in $10 \%$ formalin with $20 \%$ sucrose, sliced the next day into $50-\mu \mathrm{m}$-thick frozen sections, and thaw mounted on microscopic slides for subsequent examination and photography. If blue dye was not visible in the correct area on both sides, the data from the rat in question were excluded from analysis.

Laboratory analysis. After gentle mixing, duplicate aliquots of trunk blood were drawn into capillary tubes for the determination of hematocrit. The remaining blood was centrifuged at $3,000 \mathrm{rpm}$ and $4^{\circ} \mathrm{C}$ for $20 \mathrm{~min}$. Plasma was removed by aspiration and analyzed immediately for osmolality by freezing point depression using macrocuvettes (model 3R, Advanced Instruments, Inc., Needham Heights, MA). Plasma glucose, sodium, potassium, urea, and creatinine were determined by an autoanalyzer (analyzer model ASTRA, Beckman Instruments, Inc., Fullerton, CA). The remaining plasma was stored at $-20^{\circ} \mathrm{C}$ and assayed within $1-2$ wk for vasopressin, using a modification (22) of our original method (23). This assay has a sensitivity of 0.1 pg per tube with $50 \%$ displacement at 1.9 pg per tube and gives absolute values identical to those obtained with our original assay (23).

Data analysis. All results were expressed as the mean $\pm \mathrm{SE}$ of the mean. Differences were compared statistically by one-way analysis of variance with Duncan's multiple range test using SAS/STAT statistical program (SAS Institute Inc., Cary, NC). Differences were considered to be significant if $P<0.05$. The decrease in blood volume (BV) was calculated by the standard formula: $(\mathrm{BV} 2 / \mathrm{BV} 1)=($ Hct1 $/$ Hct 2$)$ $\times 100(24)$.

\section{Specific experimental protocols}

Experiment I: the relative effects of s.c. and i.c.v. injection of diprenorphine on the plasma vasopressin response to acute hypovolemia. Rats with chronically implanted i.c.v. cannulae were divided into six groups. Group 1 (normovolemic, untreated controls), was injected i.p., s.c., and i.c.v. with normal saline. Group 2 (hypovolemic, untreated controls) was injected i.p. with PEG and injected s.c. and i.c.v. with normal saline. Groups 3-6 (hypovolemic, treated) were injected i.p. with PEG and injected s.c. or i.c.v. with normal saline or diprenorphine at a dose of either 0.22 or $2.2 \mathrm{nmol} / \mathrm{kg}$. The i.p. injections were given $60 \mathrm{~min}$ before the s.c. and i.c.v. injections and $90 \mathrm{~min}$ before sacrifice.

Experiment II: the effect of diprenorphine microinjected into the NTS on plasma vasopressin under conditions of eulovemia and acute hypovolemia. Rats were divided into four groups. Group 1 (normovolemic, untreated controls) was given normal saline i.p. and into the NTS. Group 2 (normovolemic, treated) was given normal saline i.p. and diprenorphine $(0.11 \mathrm{nmol} / \mathrm{kg})$ into the NTS. Group 3 (hypovolemic, untreated controls) was given PEG i.p. and normal saline into the NTS. Group 4 (hypovolemic, treated) was given PEG i.p. and diprenorphine $(0.11 \mathrm{nmol} / \mathrm{kg})$ into the NTS. The i.p. injections were given $60 \mathrm{~min}$ before the NTS injections and $90 \mathrm{~min}$ before sacrifice.

Experiment III: the effect of diprenorphine microinjected into the $P B N$ on plasma vasopressin under conditions of euvolemia and acute hypovolemia. Rats were divided into four groups. Group 1 (normovolemic, untreated controls) was given normal saline i.p. and into the PBN. Group 2 (normovolemic, treated) was given normal saline i.p. and diprenorphine $(0.11 \mathrm{nmol} / \mathrm{kg}$ ) into the PBN. Group 3 (hypovolemic, untreated controls) was given PEG i.p. and normal saline into the 
PBN. Group 4 (hypovolemic, treated) received PEG i.p. and diprenorphine $(0.11 \mathrm{nmol} / \mathrm{kg})$ in the PBN. The i.p. injections were given 60 min before the PBN injections and $90 \mathrm{~min}$ before sacrifice.

Experiment IV: The effect of different doses of diprenorphine microinjected into the PBN on the plasma vasopressin response to acute hypovolemia. Rats were divided into five groups. Group 1 (normovolemic, untreated controls) received normal saline i.p. and in the PBN. Group 2 (hypovolemic, untreated controls) received PEG i.p. and normal saline in the PBN. Groups 3-5 (hypovolemic, treated) received PEG i.p. and either of three different doses of diprenorphine $(0.055$, 0.11 , or $0.22 \mathrm{nmol} / \mathrm{kg}$ ) in the PBN. The i.p. injections were given 60 min before the PBN injections and 90 min before sacrifice.

Experiment $V$ : The effect of diprenorphine microinjected into the $P B N$ on the plasma vasopressin response to hyperosmolality. Rats were divided into three groups. Group 1 (normoosmotic, untreated controls) received normal saline i.p. and in the PBN. Group 2 (hyperosmotic, untreated controls) received hypertonic saline i.p. and normal saline in the PBN. Group 3 (hyperosmotic, treated) received hypertonic saline i.p. and diprenorphine $(0.11 \mathrm{nmol} / \mathrm{kg})$ in the PBN. The i.p. injections were given immediately after the PBN injections and 30 min before sacrifice.

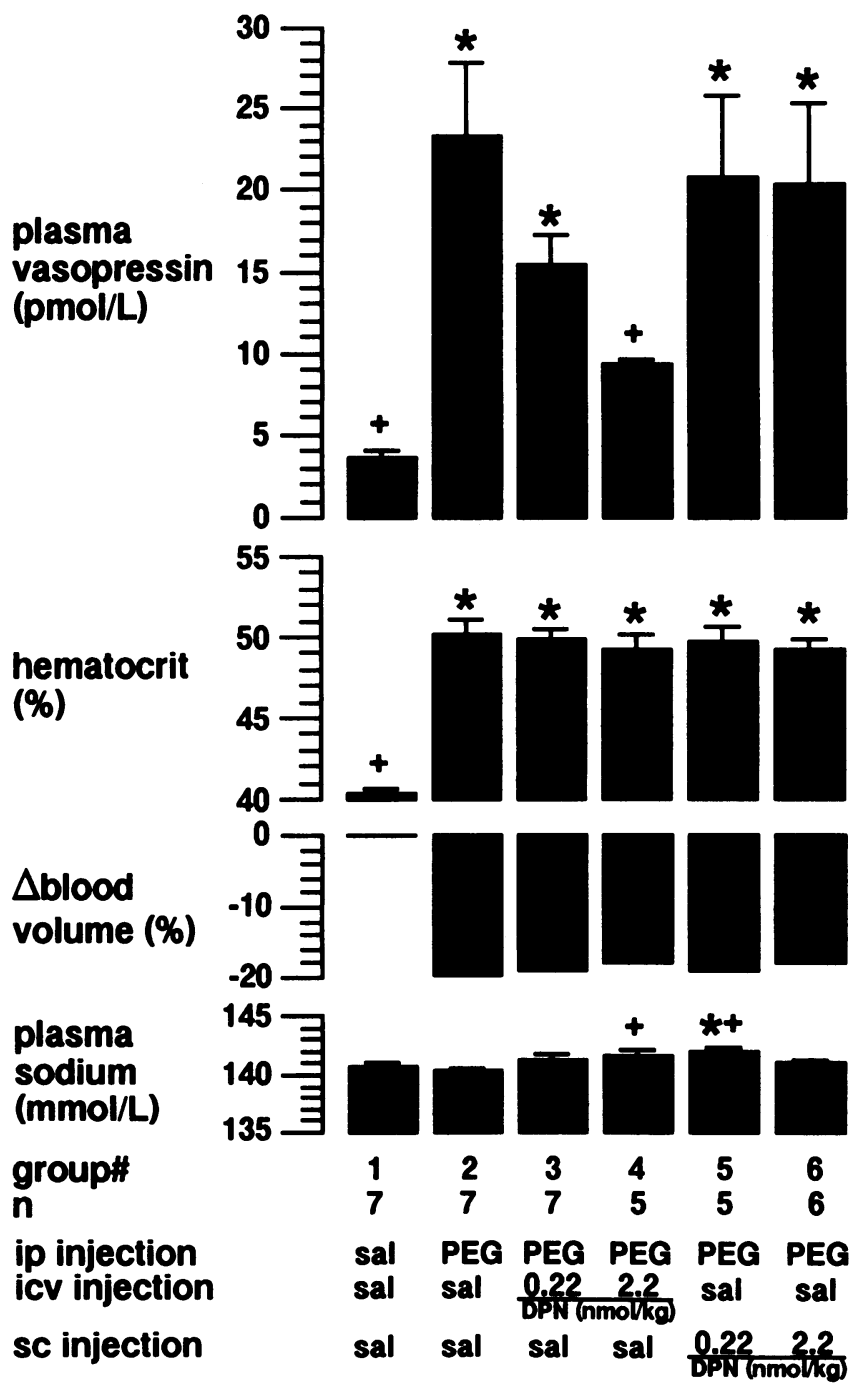

Figure 1. The relative effect of i.c.v. and s.c. injection of diprenorphine on the plasma vasopressin response to acute hypovolemia. *Significant difference from the euvolemic sham-treated rats (Group 1). ${ }^{+}$Significant difference from the hypovolemic sham-treated rats (group 2). Abbreviations: sal, saline; DPN, diprenorphine.

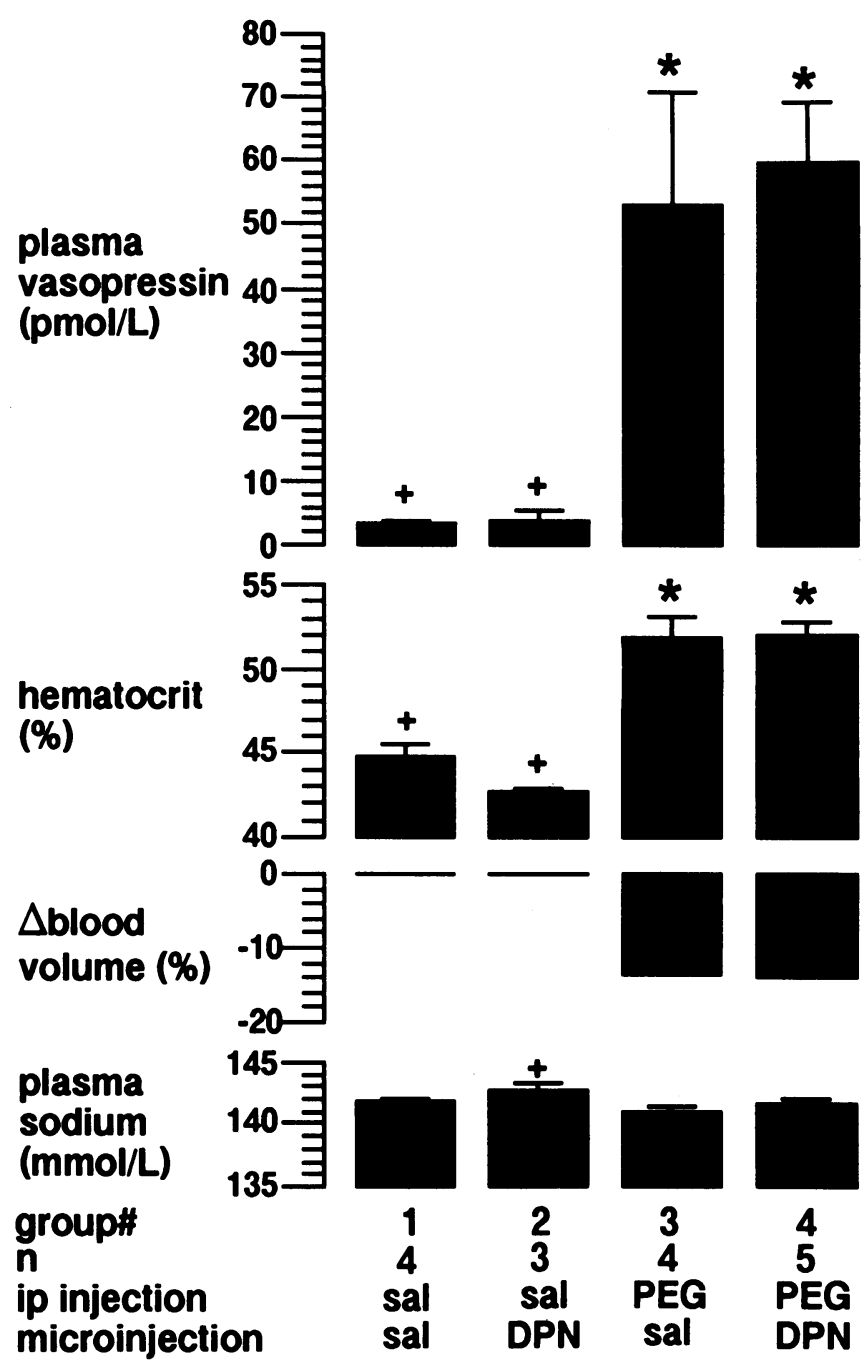

Figure 2. Effect of diprenorphine in the NTS on plasma vasopressin under euvolemic and hypovolemic conditions. Symbols and abbreviations as in Fig. 1.

Experiment VI: the effect of diprenorphine microinjected into the $P B N$ on the plasma vasopressin response to acute hypotension. Rats were divided into three groups. Group 1 (normotensive, untreated controls) received normal saline s.c. and in the PBN. Group 2 (hypotensive, untreated controls) received sodium nitroprusside s.c. and normal saline in the PBN. Group 3 (hypotensive, treated) received sodium nitroprusside s.c. and diprenorphine $(0.11 \mathrm{nmol} / \mathrm{kg})$ in the PBN. The PBN was microinjected $20 \mathrm{~min}$ before the s.c. injection and $30 \mathrm{~min}$ before sacrifice.

Experiment VII: the effects of naloxone or ICI-154,129 microinjected into the PBN on the plasma vasopressin response to acute hypovolemia. Rats were divided into four groups. Group 1 (normovolemic, untreated controls) received normal saline i.p. and in the PBN. Group 2 (hypovolemic, untreated controls) received PEG i.p. and normal saline in the PBN. Group 3 (hypovolemic, treated) received PEG i.p. and naloxone $(0.11 \mathrm{nmol} / \mathrm{kg})$ in the PBN. Group 4 (hypovolemic, treated) received PEG i.p. and ICI-154,129 $(0.11 \mathrm{nmol} / \mathrm{kg})$ in the PBN. The i.p. injection was given $60 \mathrm{~min}$ before the PBN injections and $90 \mathrm{~min}$ before sacrifice.

Experiment VIII: The effect of $U-50,488 H$ microinjected into $P B N$ on plasma vasopressin under conditions of euvolemia and acute hypovolemia. Rats were divided into four groups. Group 1 (normovolemic, untreated controls) received normal saline i.p. and in the PBN. Group 2 (normovolemic, treated) received normal saline i.p. and U-50,488H 
$(0.14 \mathrm{nmol} / \mathrm{kg}$ ) in the PBN. Group 3 (hypovolemic, untreated controls) received PEG i.p. and normal saline in the PBN. Group 4 (hypovolemic, treated ) received PEG i.p. and U-50,488H $(0.14 \mathrm{nmol} / \mathrm{kg})$ in the PBN. The i.p. injection was given $60 \mathrm{~min}$ before the PBN injections and $90 \mathrm{~min}$ before sacrifice.

\section{Results}

Experiment $I$. In rats with acute hypovolemia induced by i.p. injection of PEG (groups 2-6), the resultant increase in plasma vasopressin was significantly less in the group in which 2.2 $\mathrm{nmol} / \mathrm{kg}$ of diprenorphine was injected i.c.v. (Fig. 1). Injection i.c.v. of a 10-fold lower dose of the drug also appeared to slightly inhibit the rise in vasopressin but the value did not differ significantly from that in the untreated, hypovolemic rats (group 2). The inhibitory effect of the i.c.v. injection of diprenorphine was not associated with any decrease in plasma sodium or the degree of hypovolemia as indicated by the rise in hematocrit. Indeed, plasma sodium was actually slightly higher in the rats (group 4) in which plasma vasopressin was decreased by i.c.v. injection of diprenorphine. When injected s.c., neither dose of diprenorphine had any effect on the plasma vasopressin response to acute hypovolemia. Compared to the euvolemic or hypovolemic controls (group 1 or 2), plasma sodium was slightly higher in the rats injected s.c. with the lower dose of diprenorphine (group 5 ) but not in those receiving the higher dose (group 6). In the five groups of rats with PEG-induced hypovolemia, plasma osmolality was also higher (range 303-305 mmol $/ \mathrm{kg}$ ) than in the normovolemic, shamtreated controls $(299 \mathrm{mmol} / \mathrm{kg}$, group 1) but this difference was due largely to a slightly higher plasma urea (range 8.6-10.1 $\mathrm{mM}$ in PEG treated rats vs. $7.4 \mathrm{mM}$ in control rats). Plasma glucose was similar in all six groups (range 7.7-8.1 mM).

Experiment II. In normovolemic control rats injected i.p. with normal saline (groups 1 and 2), basal plasma vasopressin, hematocrit, and plasma sodium did not differ in the groups in which diprenorphine or saline was microinjected into the NTS (Fig. 2). In the rats injected i.p. with PEG (groups 3 and 4), plasma vasopressin and hematocrit were significantly higher than in the controls (groups 1 and 2) and neither variable differed in the groups given diprenorphine or saline vehicle into the NTS. Plasma osmolality and urea were again slightly higher in the PEG-treated groups than in the controls $(305 \pm 3$ and $307 \pm 2$ vs. $297 \pm 1$ and $300 \pm 2 \mathrm{mmol} / \mathrm{kg} ; 9.0 \pm 0.9$ and $10.1 \pm 1.3$ vs. $6.5 \pm 0.4$ and $7.6 \pm 1.1 \mathrm{mmol} / \mathrm{kg}$ ) but the values did not differ in the groups given saline or diprenorphine in the NTS. Plasma sodium was slightly higher in group 2 than in group 3 but it did not differ in the sham and diprenorphine-treated groups. Similar negative results were obtained in a repeat experiment. In both studies, the magnitude of the vasopressin responses in the sham and drug-treated hypovolemic groups were almost twofold greater than in any of the other experiments, even though plasma sodium and the reduction in blood volume were about the same. Inspection of brain slices confirmed that the injectate containing the methylene blue dye was concentrated in the intermediate portion of the NTS (Fig. 3 ).

Experiment III. In normovolemic control rats injected i.p. with normal saline (groups 1 and 2), basal plasma vasopressin, hematocrit, and plasma sodium did not differ between the groups in which saline or $0.11 \mathrm{nmol} / \mathrm{kg}$ of diprenorphine was injected into the PBN (Fig. 4). However, in the rats in which hypovolemia was induced by i.p. injection of PEG (groups 3 and 4), the resultant increase in plasma vasopressin was almost $50 \%$ less in the group in which diprenorphine was microinjected into the PBN. This inhibition was not associated with a demonstrable decrease in plasma sodium or the level of hypovolemia as indicated by the rise in hematocrit. As in the other experiments, the rats injected with PEG had slightly higher levels of plasma osmolality ( $304 \pm 2$ and $304 \pm 1$ vs. $300 \pm 1$ and $300 \pm 0 \mathrm{mmol} / \mathrm{kg})$ and urea $(8.4 \pm 0.5$ and $8.0 \pm 0.4$ vs. $6.7 \pm 0.4$ and $6.9 \pm 0.3 \mathrm{mmol} / \mathrm{kg}$ ) and neither variable differed in the diprenorphine- and sham treated groups. Plasma glucose was
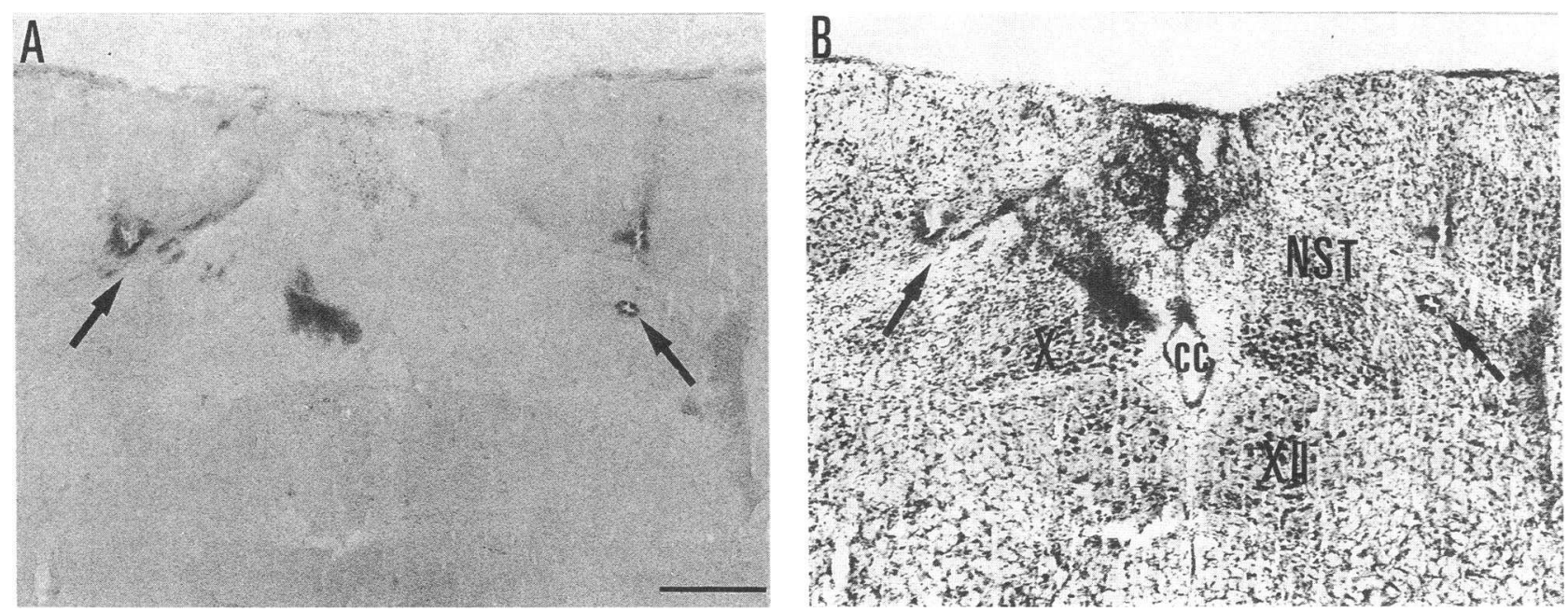

Figure 3. Coronal sections of rat brain showing the area in which microinjection of diprenorphine did not affect basal or volume stimulated plasma vasopressin. $(A)$ Unstained section through the injection sites, in which each needle track can be seen to end in a small dye spot (arrows). A small hemorrhage is visible in the nucleus of the solitary tract medial to the injection site on the left. $(B)$ Same section after thionin counterstaining. It can be seen that both injection sites (arrows) were placed into the dorsal part of the nucleus of the solitary tract, just medial to the solitary tract itself. Abbreviations: cc, central canal; NST, nucleus of the solitary tract; X, dorsal motor vagal nucleus; XII, hypoglossal nucleus. Scale bar $A, 350 \mu \mathrm{m}$. 
similar in all four groups (range 7.6-8.2 mM). Inspection of the brain slices from rats in which microinjection of diprenorphine inhibited the plasma vasopressin response to acute hypovolemia revealed that the injectate containing the methylene blue dye was concentrated in the dorsolateral part of the PBN (Fig. 5). Nearly identical results were obtained in a repeat experiment (not shown). In the latter study, two drug-treated rats were excluded from analysis because, in one, the microinjection missed the PBN on the right side and, in the other, both injections were in the medial division of the PBN. Their plasma vasopressin levels ( 41 and $38 \mathrm{pM}$ ) were above the range in the sham-injected as well as drug-injected, hypovolemic groups (19.9 \pm 4.5 vs. $12.2 \pm 1.8 \mathrm{pM}$, respectively).

Experiment $I V$. In rats with acute, PEG-induced hypovolemia (groups 2-5), the resultant rise in plasma vasopressin was least in the group in which the total dose of diprenorphine microinjected into the PBN was $0.11 \mathrm{nmol} / \mathrm{kg}$ (Fig. 6). In the groups receiving half or twice this dose of diprenorphine (group 3 or 5), plasma vasopressin was less inhibited but some

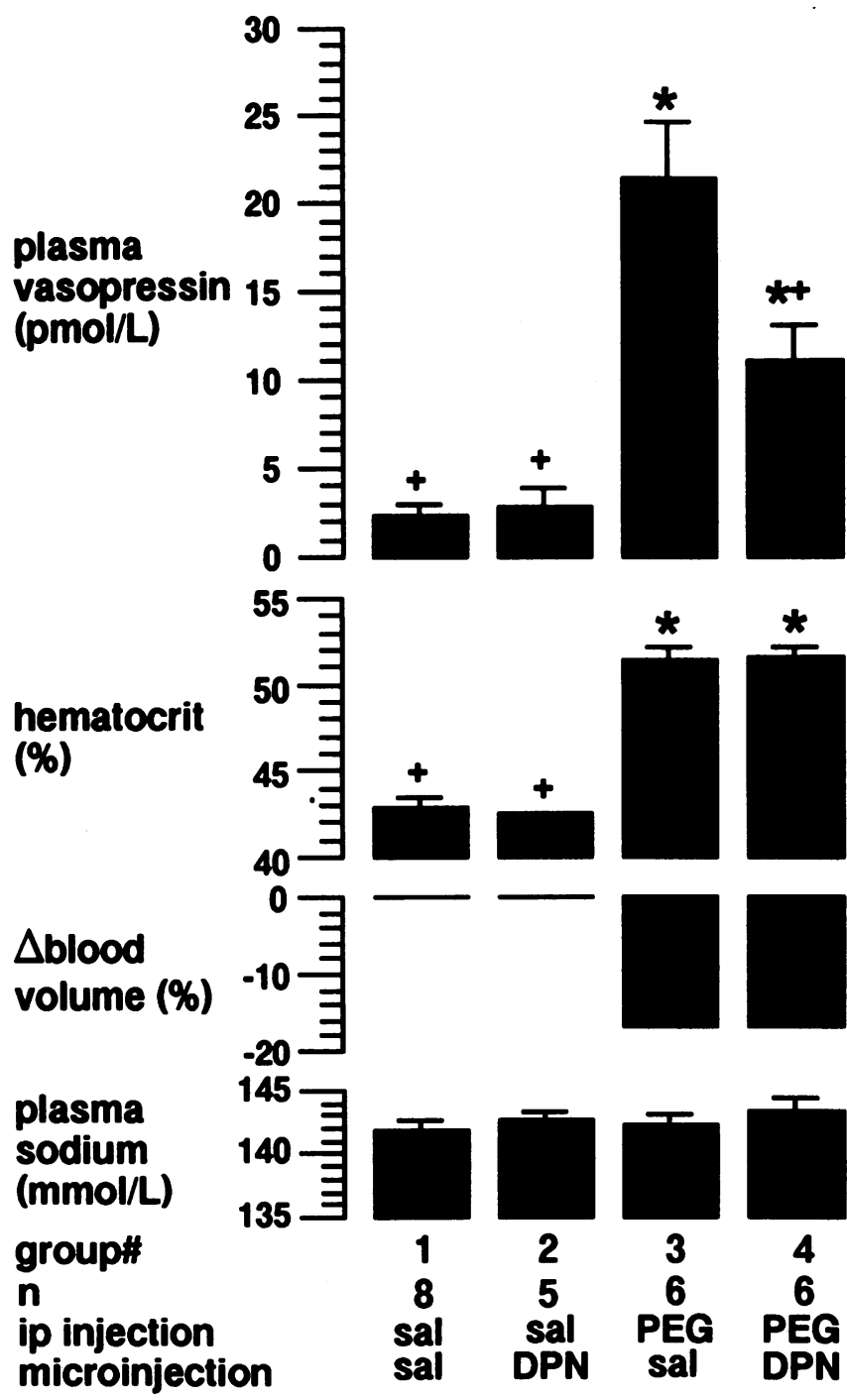

Figure 4. Effect of diprenorphine in the PBN on plasma vasopressin under euvolemic and hypovolemic conditions. Symbols and abbreviations as in Fig. 1. effect was still apparent, at least at the higher dose. As in the other experiments, the inhibitory effects of diprenorphine were not associated with any differences in hematocrit or plasma sodium. Plasma osmolality and urea were again slightly higher in the four PEG-treated groups and neither was affected by diprenorphine treatment. As in the other PBN microinjection experiment, mean plasma vasopressin in the rats receiving the maximally effective inhibitory dose of diprenorphine (group 4) appeared to be higher than in the normovolemic controls (group 1) but the difference was not statistically significant. Two rats in the group injected with $0.11 \mathrm{nmol} / \mathrm{kg}$ of diprenorphine were excluded from analysis because the microinjection missed the PBN on one side. Their plasma AVP levels (49 and $38 \mathrm{pM}$ ) were within the range found in the sham-treated hypovolemic controls (group 3 ).

Experiment $V$. In rats injected i.p. with hypertonic (600 $\mathrm{mmol} / \mathrm{kg}$ ) saline (groups 2 and 3), plasma vasopressin as well as plasma osmolality and plasma sodium were higher than in the controls (group 1) injected i.p. with isotonic saline (Fig. 7). The increases in plasma vasopressin as well as osmolality and sodium were similar in the groups in which saline or 0.11 $\mathrm{nmol} / \mathrm{kg}$ of diprenorphine were microinjected into the PBN. Hematocrit as well as plasma urea and glucose were similar in all three groups.

Experiment $V I$. In rats with acute hypotension induced by s.c. injection of sodium nitroprusside (groups 2 and 3), plasma vasopressin as well as plasma glucose were higher than in the normotensive controls (group 1) (Fig. 8). The increases in plasma vasopressin and glucose induced by hypotension did not differ in the groups in which saline or $0.11 \mathrm{nmol} / \mathrm{kg}$ of diprenorphine were injected into the PBN. Plasma sodium and hematocrit were similar in all three groups.

Experiment VII. In the rats with PEG-induced hypovolemia, the resultant increase in plasma vasopressin appeared to be slightly greater in those given PBN injections of naloxone (group 3) than ICI-154,129 (group 4) or saline vehicle (group 2) (Fig. 9). However, the values in group 3 were not significantly different from those in the sham-treated hypovolemic controls. The failure of these antagonists to alter the vasopressin response to hypovolemia was not attributable to any countervailing differences in plasma sodium or blood volume as indicated by the hematocrit. There were also no differences in plasma osmolality, urea, or glucose among the PEG-treated groups (not shown).

Experiment VIII. In normovolemic control rats injected i.p. with normal saline (groups 1 and 2), basal plasma vasopressin, hematocrit, and plasma sodium were within normal limits and did not differ in those in which the PBN was injected with saline or $0.14 \mathrm{nmol} / \mathrm{kg}$ of U-50,488H (Fig. 10). In the rats with PEG induced hypovolemia (groups 3 and 4), plasma vasopressin as well as hematocrit were higher than in the normovolemic controls and neither variable differed in the groups in which saline or U-50,488H were injected into the PBN. The failure of $\mathrm{U}-50,488 \mathrm{H}$ to affect plasma vasopressin was not associated with any countervailing difference in plasma sodium. The groups with PEG induced hypovolemia had slightly higher levels of plasma osmolality ( $303 \pm 1$ and $304 \pm 2$ vs. $297 \pm 2$ and $297 \pm 2 \mathrm{mmol} / \mathrm{kg}$ ) and urea ( $7.9 \pm 0.6$ and $8.5 \pm 0.6$ vs. $5.9 \pm 0.4$ and $6.7 \pm 0.6 \mathrm{mM}$ ) but these values did not differ between the groups given drug or saline vehicle in the PBN. Plasma glucose was similar in all groups (range 7.9 to $8.2 \mathrm{mM}$ ). 

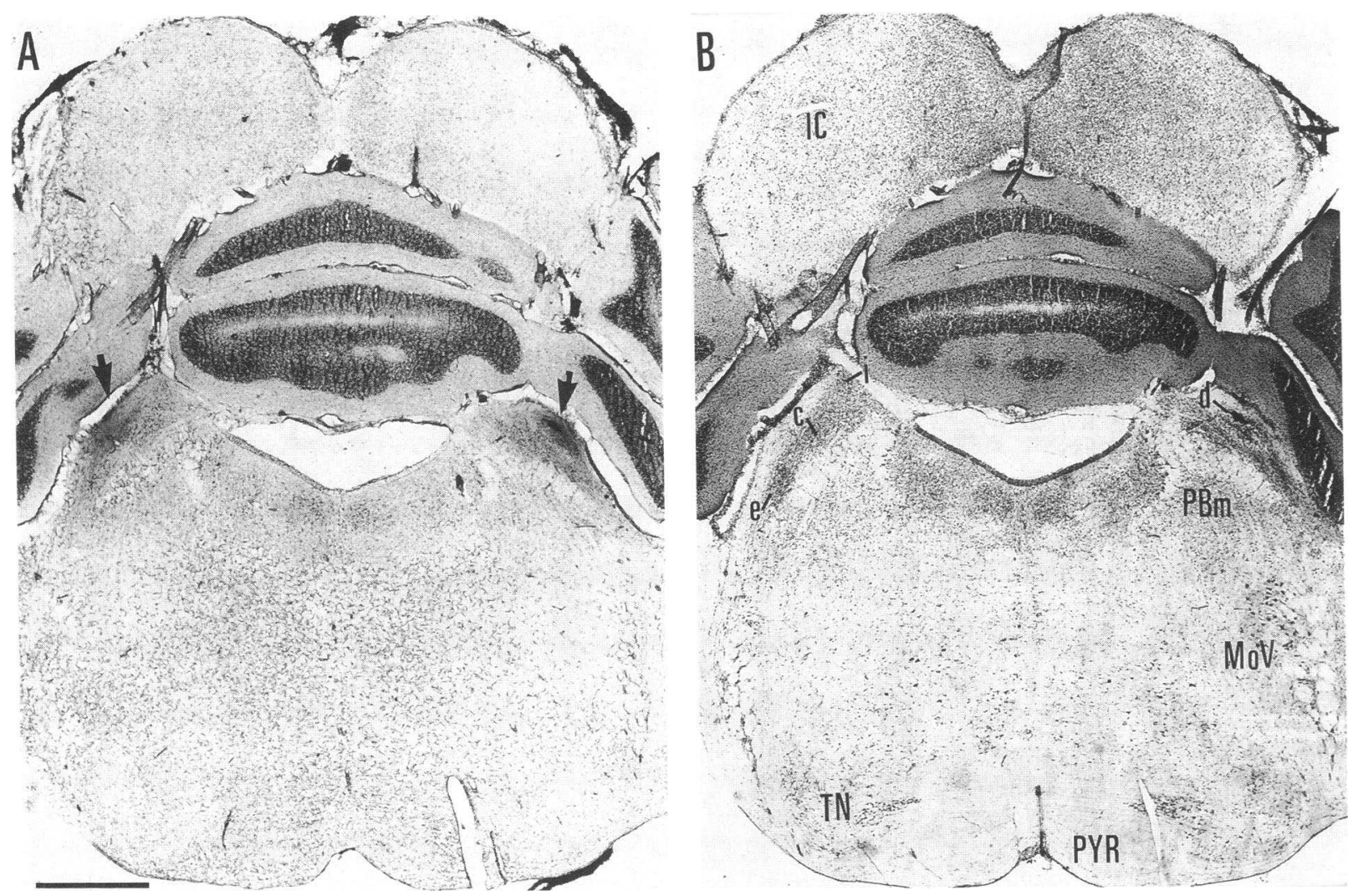

Figure 5. Coronal sections of rat brain showing areas in which microinjection of diprenorphine inhibited the vasopressin response to hypovolemia. $(A)$ Unstained section through the injection sites indicated by the two dye spots (arrows). (B) Same section after thionin counterstaining. Note that the dye spots are in the dorsal lateral subnucleus $(d)$ of the PBN just above the superior cerebellar peduncle and the medial PBN $(P B m)$. Abbreviations: MoV, motor nucleus of the trigeminal nerve; PYR, pyramidal tract; IC, inferior colliculus; TN, trapezoid nucleus; c, e, and i denote the central, external, and internal lateral nuclei, respectively.

\section{Discussion}

The results of this study support our hypothesis that diprenorphine inhibits the plasma vasopressin response to an acute hypovolemic stimulus by acting, at least in part, at a site along the neuronal pathway that transmits signals from the peripheral volume receptors to the neurohypophysis. This concept is supported by the fact that the inhibitory effect of diprenorphine was at least 10 -fold greater when the drug was given i.c.v. instead of s.c. (Fig. 1) and it was almost 200 -fold greater when it was microinjected bilaterally into the lateral PBN (Figs. 4 and 6 ). The latter effect was unlikely to be due to leakage of the injection into cerebrospinal fluid and action at a distant site because the dose which produced inhibition when injected into the PBN was $1 / 20$ of that required to have the same effect when it was injected directly into the ventricular system. The inhibition of vasopressin also cannot be attributed to a reduction in the intensity of hypovolemic or osmotic stimulation since neither hematocrit, plasma sodium, osmolality, urea, nor glucose were decreased by the diprenorphine treatment. Because of the potential confounding effects of the additional surgical instrumentation, we did not attempt to measure arterial pressure in the i.c.v. or microinjected rats. However, the inhibitory effect of diprenorphine is probably not due to a rise in blood pressure because the drug does not have this effect when given s.c. even in very large doses (7). It also cannot be attributed to activation of some nonspecific inhibitory input to the neurohypophysis because injections of the drug into the PBN had no effect on the vasopressin response to osmotic or hypotensive stimuli (Figs. 7 and 8). We conclude, therefore, that the inhibition of volume induced vasopressin secretion by diprenorphine is achieved, at least in part, by a direct action of the drug on opioidergic receptors located in or near the lateral PBN.

These observations are consistent with previous reports that the lateral PBN contains receptors for diprenorphine (25) and is a link in the reflex pathway from peripheral baroreceptors to the hypothalamus (4). Indeed, it has been shown recently that this nucleus not only receives neuronal projections from the NTS (26-29), the first brainstem synapse for vagal and glossopharyngeal afferents from peripheral baroreceptors (30), but it also sends projections to the paraventricular and median preoptic nuclei, as well as to the perinuclear zone surrounding the supraoptic nucleus (31-33), all of which are known to be involved in the regulation of vasopressin secretion. Consistent with this anatomic data, there is also functional evidence that the PBN is involved in the regulation of vasopressin secretion (13-16) as well as cardiovascular regulation (34). Hence, the results of the present study provide new, pharmacologic evidence to support a large body of prior anatomical and functional data that the PBN is a link in the neuronal pathway that subserves the hemodynamic control of vaso- 


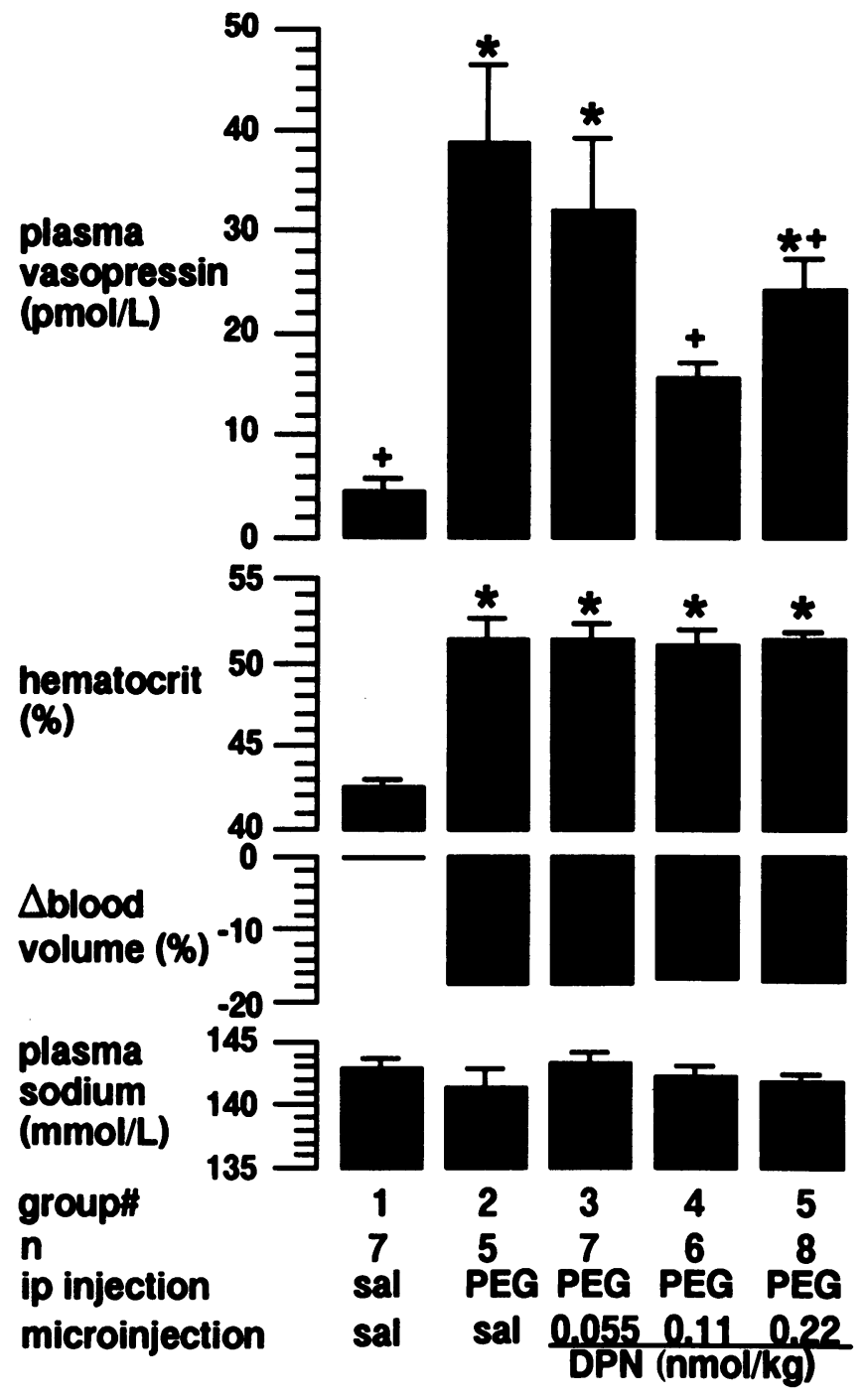

Figure 6. Effect of different doses of diprenorphine in the PBN on the plasma vasopressin response to an acute hypovolemic stimulus. Symbols and abbreviations as in Fig. 1.

pressin secretion. Our finding that injecting the PBN with diprenorphine inhibits the vasopressin response to acute hypovolemia (Figs. 4 and 6 ) but not to acute hypotension (Fig. 8 ) is noteworthy because it provides clear evidence that, at this level, the pathways conveying the two stimuli remain largely if not totally distinct. This differentiation is probably neurochemical as well as anatomic because the AVP response to a hypotensive stimulus is also unaffected when large doses of diprenorphine are given systemically (7) and is potentiated rather than diminished by electrolytic lesioning of the lateral PBN (15). Taken together, these three findings suggest that the AVP response to acute hypotension is mediated by nonopioidergic pathways located in other areas, whereas the lateral PBN contains opioid-mediated, stimulatory afferents from the low pressure, volume control system as well as inhibitory projections of uncertain character and origin. The precise location of the stimulatory and inhibitory pathways is unknown because the area covered by the lesion experiments was relatively large and the size of the dye spots found after in vitro processing of microin- jected tissue may be an unreliable indicator of the extent of drug diffusion in vivo. Probably, however, the stimulatory afferents are bilateral since the vasopressin response to hypovolemia was inhibited only when both PBN were injected with diprenorphine.

This study does not define the exact mechanism by which diprenorphine acts in the PBN to inhibit the volume control of vasopressin. However, it does indicate that the drug probably was not acting as a weak $k$ agonist (35) because the inhibitory effect of diprenorphine was not reproduced by microinjecting the PBN with a slightly higher molar dose of U-50,488H (Fig. $10)$, a potent $\kappa-1$ agonist $(18,19)$ which, when given systemically, suppresses basal as well as osmotically and hemodynamically stimulated vasopressin release (36). Presumably, therefore, the inhibitory action of diprenorphine in the PBN is due to its properties as an opioid antagonist (6). This inhibition probably is not due to antagonism of $\mu, \delta$, or $k-1$ receptors because $(a)$ microinjecting the PBN with equimolar doses of naloxone or ICI-154,129 did not inhibit the vasopressin response to acute hypovolemia (Fig. 9); and (b) microinjecting the PBN with a potent $k-1$ agonist also did not stimulate vaso-

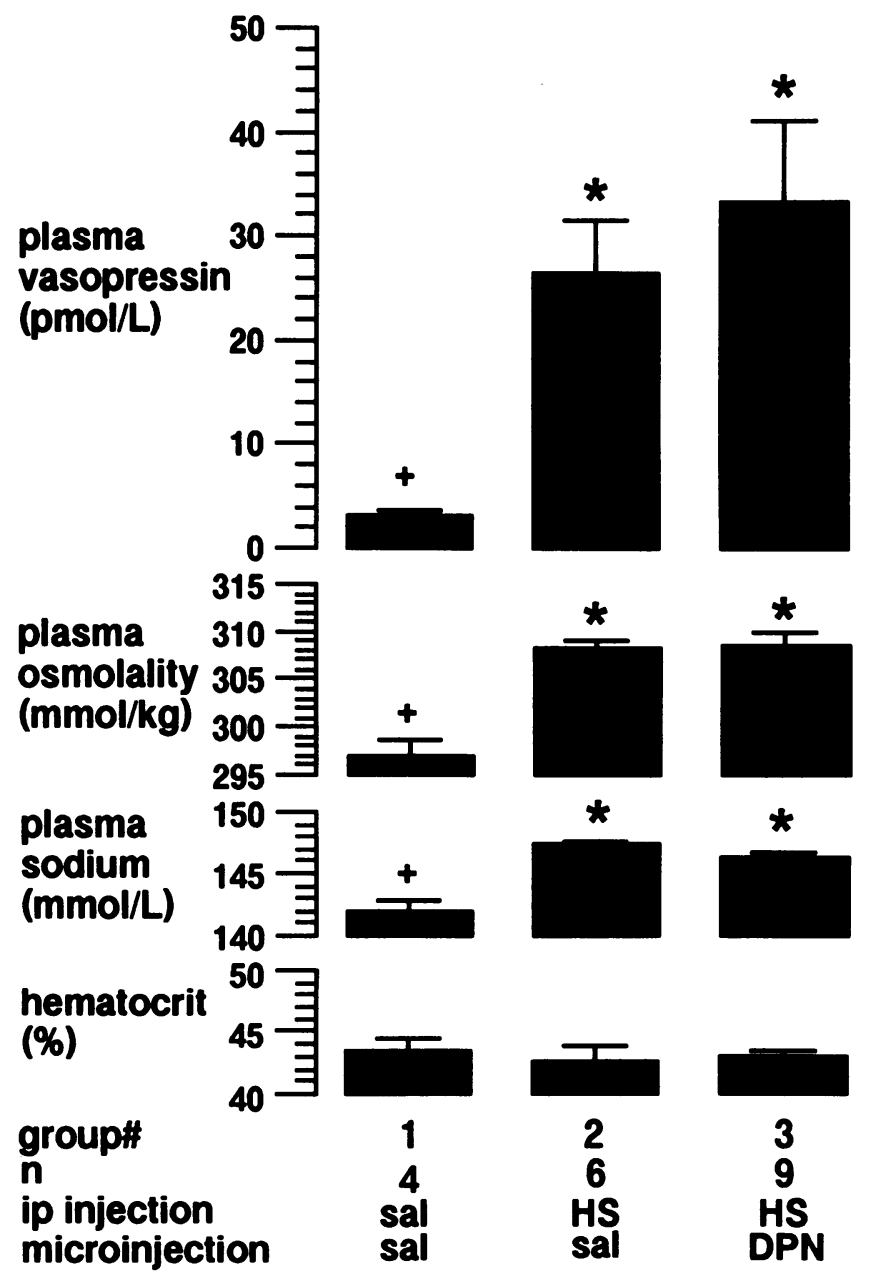

Figure 7. Effect of diprenorphine in the PBN on the plasma vasopressin response to an osmotic stimulus. Abbreviation: HS, hypertonic saline $(600 \mathrm{mmol} / \mathrm{kg})$; other symbols and abbreviations are the same as in Fig. 1. 


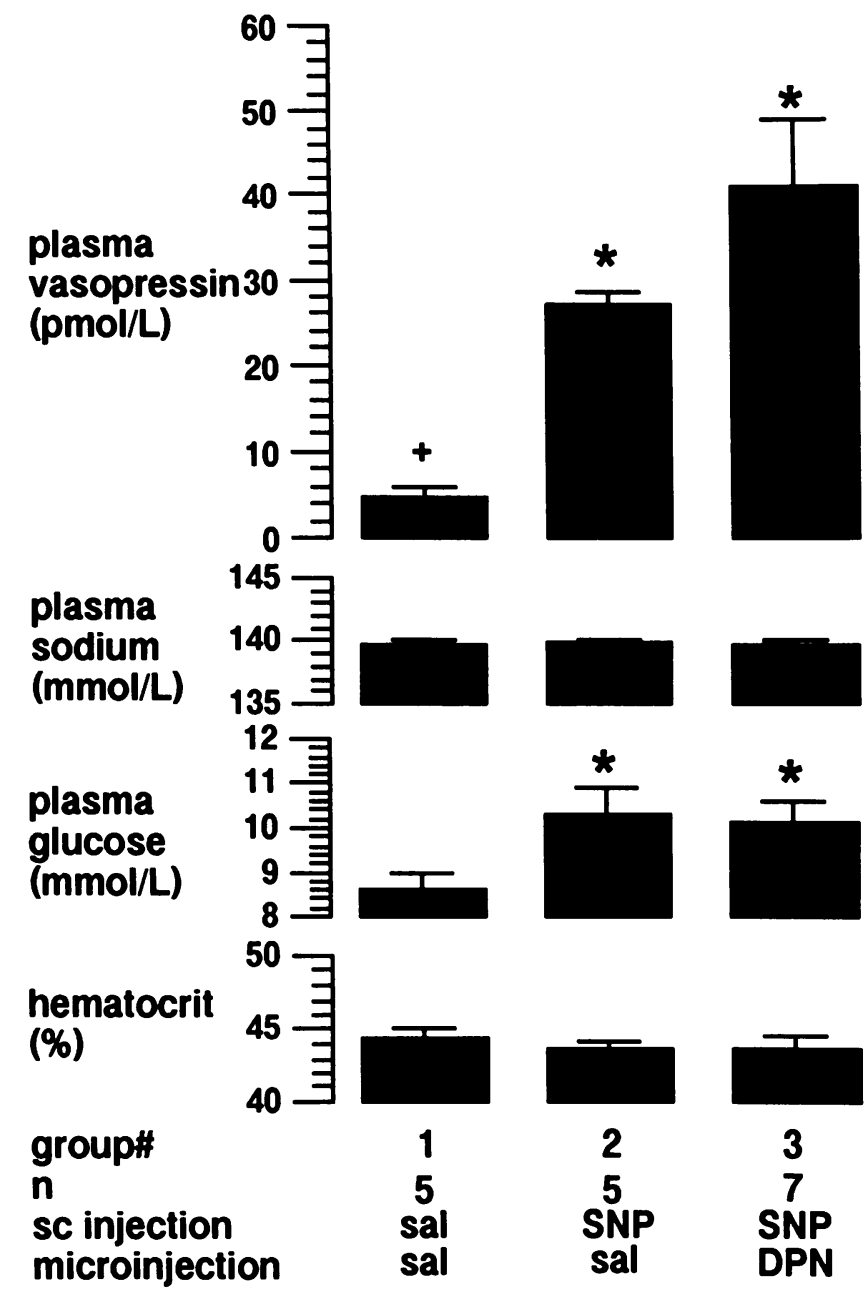

Figure 8. Effect of diprenorphine in the PBN on the plasma vasopressin response to a hypotensive stimulus. Abbreviation: SNP, sodium nitroprusside $(1 \mathrm{mg} / \mathrm{kg})$; other symbols and abbreviations are the same as in Fig. 1.

pressin secretion (Fig. 10). We postulate, therefore, that the inhibitory effect of diprenorphine in the PBN is achieved by blocking endogenous stimulation of some other class of opioid receptor, most likely the recently recognized $k-2$ or $k-3$ subtypes (19). This hypothesis is consistent with other evidence that the PBN is richly innervated with opioidergic neurons $(9,37)$, some of which originates in the NTS (27) and that it also binds large amounts of tritiated diprenorphine which cannot be completely displaced with a combination of $\mu, \delta$, and $k-1$ ligands (38). It is also consistent with the lack of a stimulatory or inhibitory effect of the $\kappa-1$ agonist, U-50,488H (Fig. 10) since this drug is reported to have a relatively low affinity for $\kappa-2$ and $\kappa-3$ receptors (19). The role of the other, more "conventional" diprenorphine binding sites in the PBN is unknown. However, the tendency of naloxone to enhance the AVP response to hypovolemia (7) (Fig. 9) raises the possibility that some $\mu$-type receptors subserve inhibitory pathways in the lateral PBN and, possibly, elsewhere. If so, the failure of microinjected diprenorphine to completely suppress plasma AVP in hypovolemic rats (Fig. 6) could be due to simultaneous blockade of this inhibitory pathway.
These studies do not exclude the possibility that diprenorphine acts at additional sites to inhibit the vasopressin response to hypovolemia. Even at maximally effective inhibitory doses of diprenorphine, plasma vasopressin in the hypovolemic rats was always slightly higher than in the euvolemic controls (Figs. 4 and 6). Although these differences were not statistically significant and could have been due simply to slight inadequacies in the size or placement of the injections, they may also signify the existence of alternative neural or humoral paths for the volume control of vasopressin secretion. If these additional pathways exist, at least some of them may also be diprenorphine sensitive since the maximum vasopressin suppression achieved when the drug was given systemically ( 7 ) appears to be greater (about $90 \%)$ than when it was given i.c.v. $(70 \%)$ or into the PBN $(60 \%)$. The apparently lesser inhibition observed when diprenorphine was injected into the PBN was not overcome by doubling the dose of the drug (Fig. 6). Indeed, the highest dose of diprenorphine seemed to reverse the partial inhibition observed with the lower dose. This biphasic effect could indicate

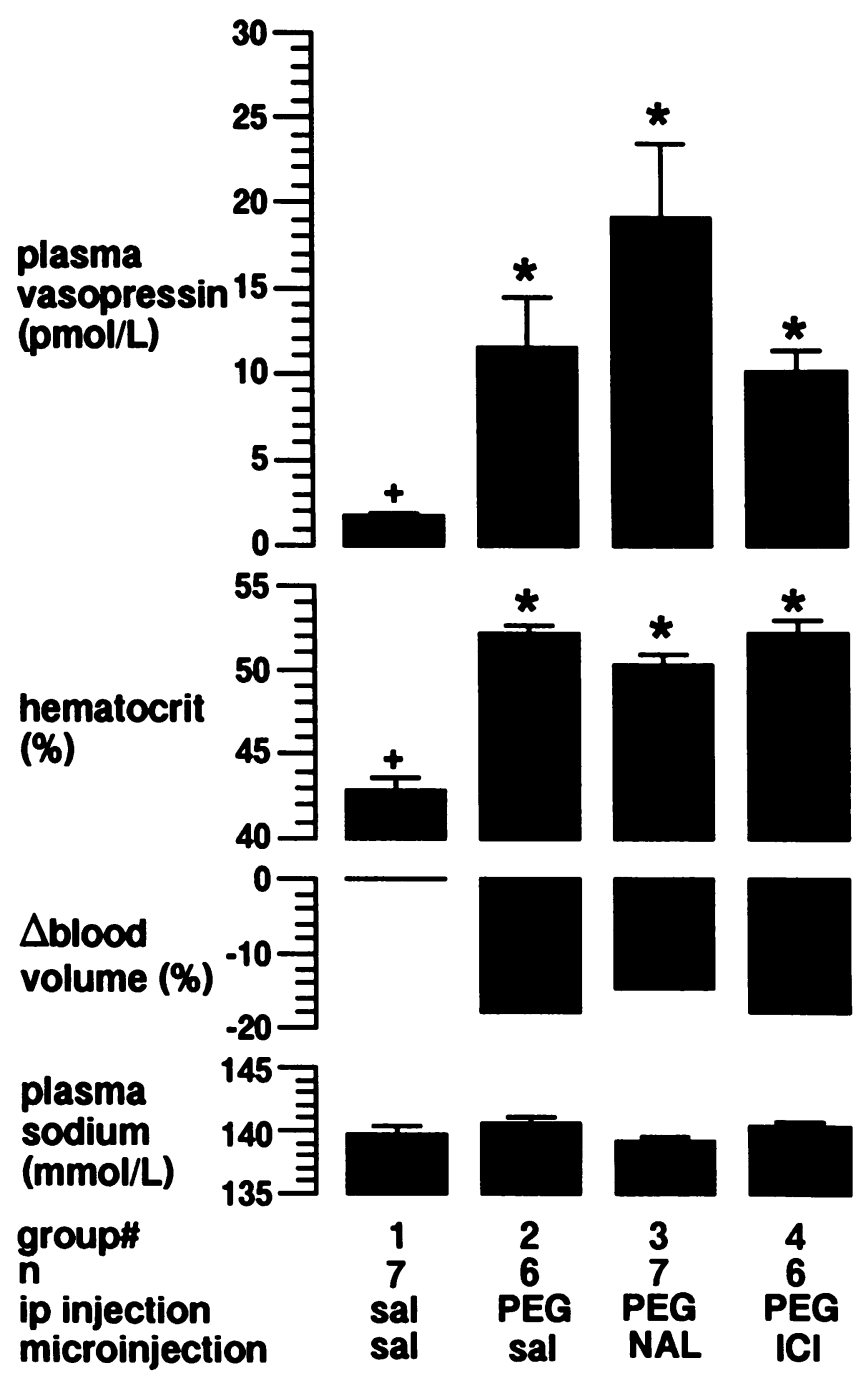

Figure 9. Effect of naloxone or ICI-154,129 in the PBN on the plasma vasopressin response to an acute hypovolemic stimulus. Abbreviation: NAL, naloxone; ICI, ICI-154,129; other symbols and abbreviations are the same as in Fig. 1. 


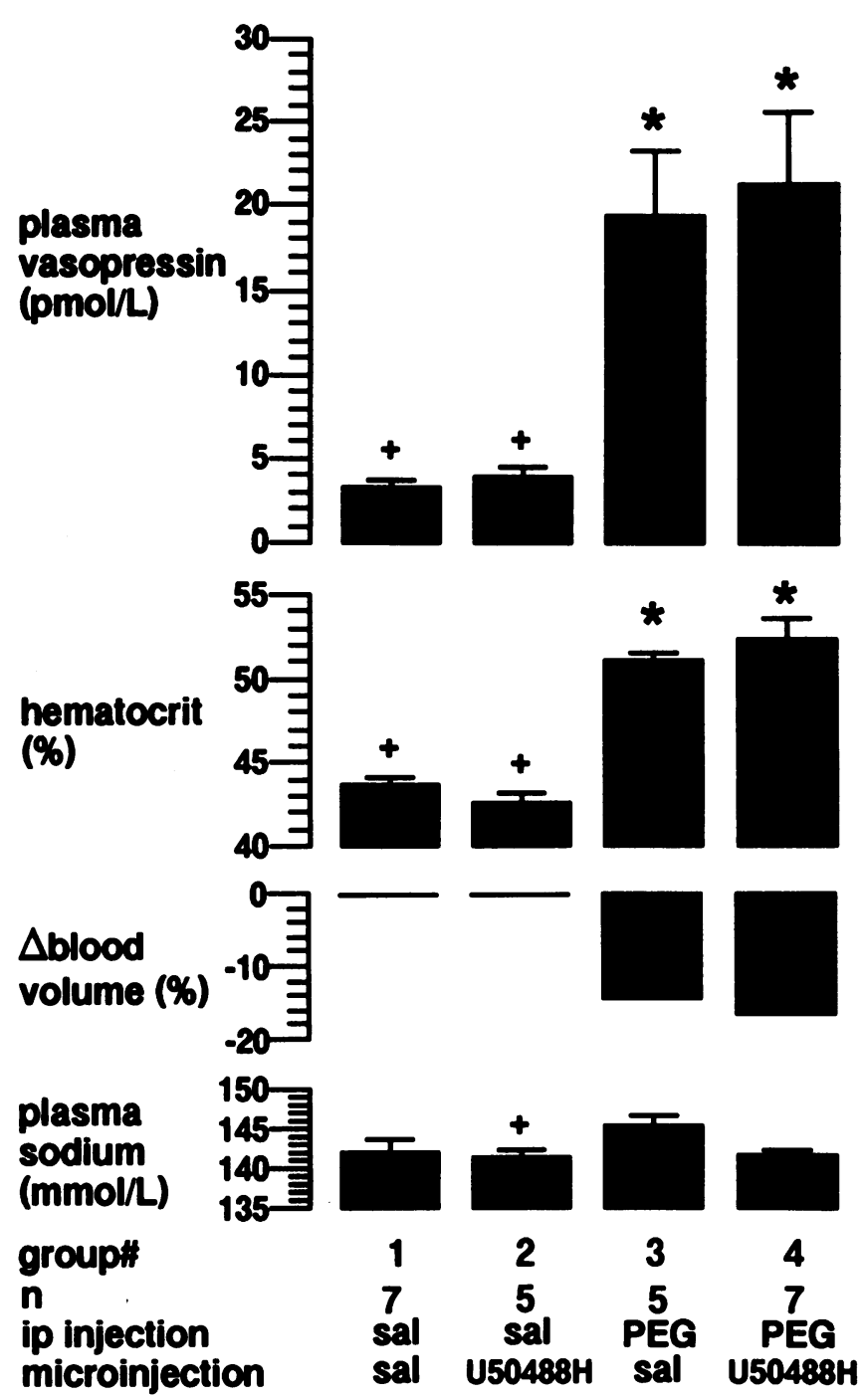

Figure 10. Effect of $\mathrm{U}-50,488 \mathrm{H}$ in the $\mathrm{PBN}$ on plasma vasopressin under euvolemic and hypovolemic conditions. Symbols and abbreviations as in Fig. 1.

that, at high doses, diprenorphine acts as a weak agonist or, perhaps like naloxone (Fig. 9), begins to antagonize the inhibitory effect of some other endogenous opioid agonist. If there are other diprenorphine sensitive sites in the system that mediates hypovolemic stimulation of vasopressin, they were not demonstrable in the intermediate part of the NTS (Fig. 2) even though this region contains a relatively high concentration of $k$ opioids (9). However, these results do not necessarily exclude a site of action in the NTS because the injections were not large enough to cover the entire nucleus. Moreover, for unknown reasons, microinjections in this area consistently enhanced the vasopressin response to the hypovolemic stimulus. Thus, the lack of effect of diprenorphine also could have been due simply to the increased intensity of the stimulus. Nevertheless, further exploration of other areas like the ventromedial area of the medulla, the subfornical organ and the medial preoptic nucleus would be worthwhile since they also receive projections from the NTS (39-41) and contain relatively high concentrations of opioid peptides and receptors $(8,9)$.

\section{Acknowledgments}

We wish to thank Dr. D. Pfohl, Endo Laboratories for the supply of naloxone, Dr. M. Rance, Imperial Chemical Industries PLC for the gift of ICI-154,129 and Dr. P. VonVoigtlander, The Upjohn Company for the gift of U-50,488H. We also wish to thank Dr. Nancy Chamberlin for her expert technical guidance.

This research was supported by grants from the National Institutes of Health, RO1-DK36467 and RO1-NS22835.

\section{References}

1. Robertson, G. L. 1977. The regulation of vasopressin function in health and disease. Recent Prog. Horm. Res. 33:333-385.

2. Bichet, D. G., and R. W. Schrier. 1984. Water metabolism in edematous disorders. Semin. Nephrol. 4:325-333.

3. Kirchheim, H. R. 1976. Systemic arterial baroreceptor reflexes. Physiol. Rev. 56:100-176.

4. Calaresu, F. R., J. Ciriello, M. M. Caverson, D. F. Cechetto, and T. L. Krukoff. 1984. Functional neuroanatomy of central pathways controlling the circulation. In Hypertension and the Brain. G. P. Guthrie, Jr., and T. A. Kotchen, editors. Futura, New York. 3-21.

5. Bisset, G. W., and H. S. Chowdrey. 1988. Control of release of vasopressin by neuroendocrine reflexes. Q. J. Exp. Physiol. 73:811-872.

6. Paterson, S. J., L. E. Robson, and H. W. Kosterlitz. 1983. Classification of opioid receptors. Br. Med. Bull. 39:31-36.

7. Robertson, G. L., Y. Oiso, T. P. Vokes, and M. B. Gaskill. 1985. Diprenorphine inhibits selectively the vasopressin response to hypovolemic stimuli. Trans. Assoc. Am. Physicians. 98:322-333.

8. Mansour, A., H. Khachaturian, M. E. Lewis, H. Akil, and S. J. Watson. 1988. Anatomy of CNS opioid receptors. Trends Neurosci. 11:308-314.

9. Khachaturian, H., M. E. Lewis, M. K. H. Schăfer, and S. J. Watson. 1985. Anatomy of the CNS opioid systems. Trends Neurosci. 8:111-119.

10. Blessing, W. W., A. F. Sved, and D. J. Reis. 1982. Destruction of noradrenergic neurons in rabbit brainstem elevates plasma vasopressin, causing hypertension. Science (Wash. DC). 217:661-663.

11. Sved, A. F. 1985. Central neural pathway in baroreceptor control of vasopressin secretion. In Vasopressin. R. W. Schrier, editor. Raven Press, New York. 443-453.

12. Carter, D. A., and S. L. Lightman. 1985. Selective cardiovascular and neuroendocrine effects of a $\kappa$-opioid agonist in the nucleus tractus solitarii of rats. J. Physiol. (Lond.). 367:363-375.

13. Sved, A. F. 1986. Pontine pressor sites which release vasopressin. Brain Res. 369:143-150.

14. Ohman, L. E., and A. K. Johnson. 1986. Lesions in lateral parabrachial nucleus enhance drinking to angiotensin II and isoproterenol. Am. J. Physiol. 251:R504-R509.

15. Ohman, L. E., R. E. Shade, and J. R. Haywood. 1990. Parabrachial nucleus modulation of vasopressin release. Am. J. Physiol. 258:R358-R364.

16. Edwards, G. L., and A. K. Johnson. 1991. Enhanced drinking after excitotoxic lesions of the parabrachial nucleus in the rat. Am. J. Physiol. 261:R1039R1044.

17. Shaw, J. S., L. Miller, M. J. Turnbull, J. J. Gormley, and J. S. Morley. 1982. Selective antagonists at the opiate delta-receptor. Life Sci. 31:1259-1262.

18. VonVoigtlander, P. F., R. A. Lahti, and J. H. Ludens. 1983. U-50,488: A selective and structurally novel non-mu (kappa) opioid agonist. J. Pharmacol. Exp. Ther. 224:7-12.

19. Clark, J. A., L. Liu, M. Price, B. Hersh, M. Edelson, and G. W. Pasternak. 1989. Kappa opiate receptor multiplicity: evidence for two U-50,488-sensitive $\kappa_{1}$ subtypes and a novel $\kappa_{3}$ subtype. J. Pharmacol. Exp. Ther. 251:461-468.

20. Dunn, F. L., T. J. Brennan, A. E. Nelson, and G. L. Robertson. 1973. The role of blood osmolality and volume in regulating vasopressin secretion in the rat. J. Clin. Invest. 52:3212-3219.

21. Barringer, D. L., and R. D. Bunag. 1990. Differential anesthetic depression of chronotropic baroreflexes in rats. J. Cardiovasc. Pharmacol. 15:10-15.

22. Barron, W. M., B. A. Stamoutsos, and M. D. Lindheimer. 1984. Role of volume in the regulation of vasopressin secretion during pregnancy in the rat. $J$. Clin. Invest. 73:923-932.

23. Robertson, G. L., E. A. Mahr, S. Athar, and T. Sinha. 1973. Development and clinical application of a new method for the radioimmunoassay for arginine vasopressin in human plasma. J. Clin. Invest. 52:2340-2352.

24. Diem, K., and C. Lenter. 1970. In Documenta Geigy Scientific Tables. Geigy, Basle. 177.

25. Atweh, S. F., and M. J. Kuhar. 1977. Autoradiographic localization of opiate receptors in rat brain. II. The brain stem. Brain Res. 129:1-12.

26. Ricardo, J., and E. T. Koh. 1978. Anatomical evidence of direct projec- 
tions from the nucleus of the solitary tract to the hypothalamus, amygdala, and other forebrain structures in the rat. Brain Res. 153:1-26.

27. Maley, B. E., and W. M. Panneton. 1988. Enkephalin-immunoreactive neurons in the nucleus tractus solitarius project to the parabrachial nucleus of the cat. Brain Res. 442:340-344.

28. Granata, A. R., and S. T. Kitai. 1989. Intracellular study of nucleus parabrachialis and nucleus tractus solitarii interconnections. Brain Res. 492:281-292.

29. Herbert, H., M. M. Moga, and C. B. Saper. 1990. Connections of the parabrachial nucleus with the nucleus of the solitary tract and the medullary reticular formation in the rat. J. Comp. Neurol. 293:540-580.

30. Kalia, M., and J. M. Sullivan. 1982. Brainstem projections of sensory and motor components of the vagus nerve in the rat. J. Comp. Neurol. 211:248-264.

31. Saper, C. B., and A. D. Loewy. 1980. Efferent connections of the parabrachial nucleus in the rat. Brain. Res. 197:291-317.

32. Fulwiler, C. E., and C. B. Saper. 1984. Subnuclear organization of the efferent connections of the parabrachial nucleus in the rat. Brain Res. Rev. 7:229259.

33. Jhamandas, J. H., K. H. Harris, and T. L. Krukoff. 1991. Parabrachial nucleus projection towards the hypothalamic supraoptic nucleus: electrophysiological and anatomical observations in the rat. J. Comp. Neurol. 308:42-50.

34. Mraovitch, S., M. Kumada, and D. J. Reis. 1982. Role of the nucleus parabrachialis in cardiovascular regulation in cat. Brain Res. 232:57-75.
35. Traynor, J. R., A. D. Corbett, H. W. Kosterlitz. 1987. Diprenorphine has agonist activity at opioid $k$-receptors in the myenteric plexus of the guinea-pig ileum. Eur. J. Pharmocol. 137:85-89.

36. Oiso, Y., Y. Iwasaki, K. Kondo, K. Taktasuki, and A. Tomita. 1988 Effect of the opioid kappa-receptor agonist U-50,488H on the secretion of arginine vasopressin. Neuroendocrinology. 48:658-662.

37. Sutin, E. L., and D. M. Jacobowitz. 1988. Immunocytochemical localization of peptide and other neurochemicals in the rat laterodorsal tegmental nucleus and adjacent area. J. Comp. Neurol. 270:243-270.

38. Morris, B. J., and A. Herz. 1986. Autoradiographic distribution in rat brain of a non-conventional binding site for the opioid $\left[{ }^{3} \mathrm{H}\right]$ diprenorphine. Brain Res. 384:362-366.

39. Raby, W. N., and L. P. Renaud. 1989. Dorsomedial medulla stimulation activates rat supraoptic oxytocin and vasopressin neurons through different pathways. J. Physiol. (Lond.). 417:279-294.

40. Shioya, M., and J. Tanaka. 1989. Inputs from the nucleus of the solitary tract to subfornical organ neurons projecting to the paraventricular nucleus in the rat. Brain Res. 483:192-195.

41. Saper, C. B., and D. Levisohn. 1983. Afferent connections of the median preoptic nucleus in the rat: anatomical evidence for a cardiovascular integrative mechanism in the anteroventral third ventricular (AV3V) region. Brain Res. 288:21-31. 